\title{
REFERENCIAS HISTÓRICO-CULTURALES EN LOS ESCRITOS DE LOS JESUITAS EN EL JAPÓN DEL SIGLO XVI
}

\author{
POR
}

\section{Antonio Míguez Santa Cruz}

Departamento de Historia Moderna, Contemporánea y de América de la Universidad de Córdoba (UCO). Contratado de investigación

\section{RESUMEN}

Las relaciones de los jesuitas nos han proporcionado una valiosísima información sobre los pueblos que se proponían evangelizar. Este artículo pretende destacar el valor histórico, social y cultural que se puede extraer de estos escritos. De esta forma, se procurará ofrecer una leve visión sobre diversos aspectos del Japón de segunda mitad del siglo xvI: un mundo diametralmente opuesto al occidental y con el que los padres hubieron de convivir hasta su definitivo asentamiento.

Palabras ClaVE: Jesuitas, relaciones, Japón, conocimiento, choque cultural, valor histórico.

\section{HISTORIC AND CULTURAL REFERENCES IN JESUITS' WRITINGS IN XVI ${ }^{\mathrm{TH}}$ CENTURY JAPAN}

\begin{abstract}
Jesuits' writings have provided us a vast source of information about civilizations who intended to evangelize. The article below aims to prove the historic, social and cultural value from these relations. Thus, we give a summary view of many aspects from the $16^{\text {th }}$ century's second half in Japan: an absolutely opposite world to the West which these fathers were forced to coexist with until their final settlement.
\end{abstract}

KEY WORDS: Jesuits, relations, Japan, knowledge, culture shock, historical Value.

Recibido/Received

27-01-2012

Aceptado/Accepted 


\section{Algunas CONSIDERACIONES INICIALES}

Abordar las primeras relaciones entre japoneses y occidentales es otra de las numerosas aristas que nos esconde una Historia poco explotada por el estudioso europeo. El panorama en el caso de los españoles aún empeora, algo verdaderamente desalentador teniendo en cuenta que fueron precisamente los ibéricos, por medio de sus comerciantes y órdenes religiosas, los que hicieron por cronicar estos primeros contactos, tan trascendentales o aún más si cabe que los derivados del descubrimiento de Australia, o los muchos descubrimientos que padeció América a lo largo y ancho de su Geografía.

Es difícil explicar el porqué de estas lagunas. El acusado eurocentrismo de la historiografía tradicional ha propiciado que muchas civilizaciones o culturas paralelas hayan quedado sepultadas en lo más oscuro del pensamiento histórico. No es extraño escuchar términos como el Viejo Mundo u Occidente utilizados de manera referencial, como si ningún otro lugar alcanzara el derecho a compararse con la narración de la Vieja Europa, tan ensimismada que ha olvidado muchos lugares que, si bien no son comparables en términos generales, sí son dignos de estudio. La cuestión es que ante la irrefrenable y cada vez más evidente globalización es necesario un conocimiento del medio invasivo, distante hasta hace apenas una década y visto como mera excentricidad académica, pero necesario para explicar y entender muchos de los hechos sociales que se avecinan en el segundo cuarto de siglo XXI.

Muchos autores anglosajones, japoneses, e incluso ibéricos, ${ }^{1}$ han tratado de pasar de soslayo por el siglo ibérico japonés arguyendo, de forma más o menos expresa, que la estancia de los portugueses y españoles no tuvo repercusión en la finalización del periodo Muromachi ${ }^{2}$ y asentamiento del Clan Matsudaira hasta la Revolución Meiji. Si bien la segunda afirmación es discutible, la primera es del todo un disparate. De una forma u otra el objetivo de este artículo no es desentrañar si efectivamente la incidencia Namban tuvo calado, si su contribución en campos como la medicina, la astronomía o la navegación fue beneficiosa para los nipones, ${ }^{3}$ sino más bien observar lo observado; analizar las cartas de estos misioneros que recogieron concienzudamente, con ojos curiosos, fenómenos de otro mundo. Y es que por suerte para los interesados en la materia, entre aburridas e irrelevantes notas piadosas, tediosos tratados adoctrinantes,

\footnotetext{
${ }^{1}$ Reyes Manzano, A. 2005. «Mitos y leyendas sobre las relaciones hispano-japonesas durante los siglos XVI-XVII». Brocar 29: p. 53.

2 Etapa de la historia japonesa que coincide con la estancia de los Ashikaga en el poder (13361573). Fue precisamente Oda Nobunaga quien le puso fin, derrocando al último shogun, Ashikaga Yoshiaki, hermano de Yoshiteru.

${ }^{3}$ Para saber más, Gutiérrez, F. 1991. Japón y Occidente: Influencias recíprocas en el Arte. Sevilla. Guadalquivir Ediciones.
}

Hispania Sacra, LXVI

133, enero-junio 2014, 75-107, ISSN: 0018-215X, doi: 10.3989/hs.2013.047 
pseudo-literatura hagiográfica cargada de falacias y ficciones, hallamos tesoros en forma de anotación histórica o, simplemente, mera curiosidad antropológica.

A estos religiosos les dio tiempo para construir una inmensa amalgama de información que tuvo continuidad hasta su definitiva expulsión ya avanzado el siglo xvII. La compleja burocracia de la época hacía que periódicamente se enviasen aquí o allá diversos escritos, unos para justificar a las élites laicas sus inversiones, ya sean gobernadores de Filipinas o reyes de Portugal; otros para corresponder a los superiores religiosos de Goa u otras factorías de India o la China.

El desconocimiento por parte del investigador sobre el caudal de información que podrá manejar es un problema. En el caso que nos ocupa ha sido mayor de lo esperado, y pensando en la comodidad del lector se ha optado por llegar hasta unas fechas tempranas, en torno a 1575, cuando cae Ashikaga Yoshiteru y se advierte la ascensión de Nobunaga Oda en el caótico panorama de los Estados combatientes o Sengoku Jidai. A partir de entonces las relaciones de los padres se centran en hechos eminentemente religiosos y políticos, dejando cada vez más a un lado las descripciones de los primeros años.

\section{EL JAPÓN QUE SE ENCONTRARON}

Antes de sumergirnos en el análisis senso stricto de los documentos, pido al lector que haga el esfuerzo de pensar quiénes son sus autores y a quiénes van dirigidos; sobre qué tratan los mismos y con qué motivo se escribieron. No es baladí tal ejercicio de empatía, ya que probablemente el universo con el que toparon aquellos, por qué no decirlo, valientes religiosos, distaba de las estructuras mentales que manejaban de antemano, sin duda fruto de habladurías de unos y de otros, de fantasiosas lecturas medievales, o relatos aderezados de incultos marinos. Decía un jesuita que Japón era un país donde todo sucedía al revés, ${ }^{4}$ y ciertamente esa debía de ser la impresión que les causaba la isla a unos hombres abiertos de miras, con decenas de miles de kilómetros a su espaldas, pero novicios a la hora de enfrentarse a una cultura incomprensible, e incluso reprobable si se quiere, para quienes el catolicismo romano era la única forma de vida admisible. ${ }^{5}$

Las ansias por describir un mundo tan fantástico degeneraron en negligentes análisis que incluso llegaron a contradecirse entre unos y otros. Tan sólo hacía falta la lectura de un memorial donde se afirmase que los japoneses eran diestros

\footnotetext{
${ }^{4}$ Cabezas, A. 1994. El siglo ibérico en Japón: 37 Valladolid. Ed. UVA.

${ }^{5}$ Para saber más, López Garay, J. 1962. «La pre-evangelización de los primeros años de la evangelización». Missionalia Hispanica.
} 
en poesía para que, dos meses después, en otro se inquiriese que los mismos nipones eran torpes en tal disciplina. En el Proemio al Christiano de las relaciones de los padres de la Compañía de 1575 se llega a afirmar que:

...quando el lector viere que unas cartas contradicen a otras en referir las cualidades de la tierra de Japón, o las condiciones, usos y costumbres delos della, debe advertir que en provincia tan estendida, la cual es maior que España y Francia y Italia juntas, en un cabo abrá unas costumbres y en otro diferentes, y una parte ser estéril y la otra fértil: $y$ ansi, escribiéndose estas cartas de tan diferentes partes, cada una dize lo cierto desde donde escribe...

Seguramente este padre anónimo se sintió decepcionado al percatarse de las verdaderas dimensiones del archipiélago, si es que verdaderamente no las conocía: ni era tan grande, ni en sus diferentes daimiatos se hallaban tantas especificidades.

No obstante, también había primeras impresiones muy precisas y cargadas de buen juicio. Cualquier dato era bien recibido, y qué menos que encuadrar el nuevo territorio en el mapa:

...la isla de Japón está puesta al Norte y le tiene casi a cuarenta grados a la altura de la cabeza. Está de Goa, ciudad principal de la India, según la navegación que los portugueses hacen, a mil y trezientas leguas... (p. 78).

Así comienza La breve relación de las cosas y reynos de Japón de 1575 , una especie de memorando escrito por otro jesuita anónimo aunque no por ello carente de interés. Aquí se va a respetar el orden temático de estas relaciones, iniciadas casi siempre con el clima del lugar que describen, para después seguir con sus usos alimenticios, su sistema político, y algunas otras curiosidades sociales y militares. El memorando sigue de esta forma:

...es tierra por la mayor parte de grandes fríos, nieves, yelos, y vientos rezios, sujeta a muchos terremotos, pero es tierra muy sana: las más comunes enfermedades que en ella ay son de ojos. Tiene muchas minas de plata, especialmente en una isla cerca de Sacay llamada Sacayama. Críanse en ella muchos y buenos cavallos. No se coge mucho trigo, porque la gente no se da a labrar las tierras. Cógese mucho arroz allá por el mes de Julio, con el cual se mantienen y sustenta casi toda la gente... (p. 79).

No andaba descaminado nuestro desconocido escribiente al afirmar la frigidez de una tierra que no gozaba ni goza de temperaturas amables. Frío extremo en los meses de invierno que muda prácticamente sin transición alguna a un sofocante calor húmedo en los meses estivales. Tampoco se suele olvidar en estas relaciones la mención a los movimientos sísmicos, algo tristemente de actualidad pero que se ha ido repitiendo con la misma crudeza durante toda la historia de Japón. 
El comentario sobre la «sanidad de la tierra» se podría haber interpretado como una alusión hacia su fertilidad, si no fuera por la anotación siguiente y porque la tierra de Japón no es fértil en lo absoluto. De una forma u otra se nos dice que no se planta trigo porque la gente no acostumbra labrar. Más que la tradición de labranza de los japoneses, pueblo por otra parte abnegado y trabajador como el que más, repercute en este hecho el clima de la isla, poco propicio al secano y tendente a explotar los cultivos de regadío como se afirma con el comentario final del fragmento.

El detalle de la ceguera presuntamente masiva en los autóctonos del lugar responde relativamente a una fácil explicación. Si bien algunos escritos achacan el mal a la impiedad de los lugareños ${ }^{6}$ lo cierto es que el fenómeno está íntimamente relacionado con la dieta. En este sentido la ecuación está clara: los hábitos alimenticios de los japoneses eran más saludables que los practicados en Europa, pero también parcos en nutrientes. Esto garantizaba que la media de edad de los japoneses fuera de facto mucho más elevada que en Occidente, lo cual multiplicaba las posibilidades de ver ancianos ciegos principalmente por la falta de vitamina A.

En una carta de Francisco Xavier «A los padres y hermanos de la Compañía de Jesús en Cogoxima» el santo escribe:

...hízonos dios tanta merced en traernos a estas partes, las quales carecen destas abundancias, porque aunque quisiésemos dar estas superfluidades al cuerpo, no lo lleva la tierra, porque no matan ni comen cosa que crían. Ay también arroz y pescado aunque poco. Ay muchas yervas y frutas de que se mantienen; vive la gente muy sana a maravilla y ay muchos viejos... (p. 13).

El padre Balthasar Gago cerciora la teoría:...es aquella tierra muy esteril de mantenimientos, comen un poco de arroz, yervas o legumbres, y algunas veces pescado; carne no se come sino por maravilla... ${ }^{7}$

Mientras, Gaspar de Vilela aporta más datos al respecto:...la comida de esta gente es hojas de ravanos espolvoreadas con harina de cevada. Carece esta tierra de aceyte, miel, queso, leche, huevos, açucar, y vinagre, ni ninguna otra especie... ${ }^{8}$

${ }^{6}$ Gago, B. 1575. «Carta del padre Balthasar Gago de Japón para los padres y hermanos de la Compañía de Jesús de la India y Portugal. Septiembre 1555», en J. Íñiguez de Lequerica (ed.), Cartas que los padres y hermanos de la Compañía de Jesús escribieron: 11. Alcalá.

7 Ibídem: 13.

${ }^{8}$ Vilela, G. 1575. «De una del padre Gaspar Vilela cuando iba para Japón para los hermanos del colegio de Coimbra. Diciembre 1554», en J. Íñiguez de Laquerica (ed.), Cartas que los padres y hermanos de la Compañía de Jesús escribieron: 1. Alcalá. 
Ni que decir tiene, no se deben tomar estas referencias como datos absolutos. Las crónicas de los jesuitas se limitaron a observar la alimentación de las clases más deprimidas, siendo una obviedad que los estratos acomodados, léase samuráis, bonzos o funcionarios de la corte, sí que disfrutarían de manjares privativos de su casta. ${ }^{9}$ Con todo ello, el lector ya se puede ir haciendo una idea de la austeridad de estas gentes, condenadas a una dieta magra y sometidas a una presión constante por parte de los señores feudales.

El mismo Gaspar Vilela nos relata unos años más tarde cierta práctica que guarda una estrecha relación con este fenómeno:...usan (los japoneses) una extraña crueldad con sus hijos, que es matallos cuando son pequeños, porque dizen que les basta uno o dos para perpetuar la familia... ${ }^{10}$

Esta práctica se trataba de un mecanismo de protección familiar que perseguía el objetivo de optimizar los limitados recursos disponibles. Es cierta la existencia de alternativas, como por ejemplo brebajes ${ }^{11}$ abortivos, aunque éstos bien podrían entrañar serios riesgos para la salud de la madre, sobre todo en un contexto donde la medicina era una disciplina más cercana a la herboristería que una ciencia. ${ }^{12}$

A pesar de estos comportamientos alientados por el demonio, los religiosos guardaban muy buen concepto de los nipones. Son innumerables los escritos donde se ensalzan las virtudes de la raza japonesa, algunos firmados por el mismísimo Francisco, como este memorial a Kagoshima donde expresaba que:

...la gente con la que hemos conversado es la mejor que hasta ahora esta descubierta... me parece que entre gente infiel no se ha hallado otra que les haga ventaja. Es gente de muy buena conversación, generalmente buena y no maliciosa, gente de honra y mucha maravilla, y estiman más la honra que ninguna otra cosa. ${ }^{13}$

A nadie extrañará que el navarro afirme la honorabilidad de los japoneses, algo aún aplicable hoy día y tópico profundamente arraigado en el imaginario colectivo occidental. Esto se podría explicar en gran parte gracias a la figura del samurai, compendio de virtudes guerreras y morales desarrolladas a raíz

${ }^{9}$ Aquí cabe destacar el gusto de Nobunaga Oda por la comida y el vino occidentales, al que curiosamente llamaba sake rojo o namban no sake.

${ }^{10}$ Vilela, G. 1575. «De Japón para los padres y hermanos de la Compañía de Jesús de la India y Europa. Octubre 1557», en J. Íñiguez de Laquerica (ed.), Cartas que los padres y hermanos de la Compañía de Jesús escribieron: 9. Alcalá.

${ }^{11}$ Ídem.

${ }^{12}$ Cabezas, A. 1994: 55.

${ }^{13}$ Xavier, F. 1575. «Carta que el padre maestro Francisco mandó para los padres y hermanos de la Compañía de Jesús de Kagoshima, en Japón. Noviembre 1549», en J. Íñiguez de Laquerica (ed.), Cartas que los padres y hermanos de la Compañía de Jesús escribieron: 4. Alcalá.

Hispania Sacra, LXVI

133, enero-junio 2014, 75-107, ISSN: 0018-215X, doi: 10.3989/hs.2013.047 
del Bushido, o camino del guerrero. A pesar de esto hubo japoneses déspotas y crueles, algo natural entendiendo el estricto sistema de clases que servía para dividir a la sociedad japonesa. Los estratos superiores podían imponerse con total impunidad, hasta un grado que roza la despersonalización de los heimin: ${ }^{14}$ personas resignadas y temerosas del larguísimo periodo de guerras que vivían, y sin posibilidad fáctica de hacer mal a nadie considerando su hermético sistema existencial. Es fácil entender, pues, la predisposición de éstos para abrazar el mensaje de Cristo, al final un soplo de esperanza que hablaba de igualdad, amor al prójimo, y un mundo mejor que éste. Al menos sobre el papel.

Llegados al punto de analizar el complejo sistema social del Quinientos japonés, se advierte lo que sigue. Es muy probable que si un profano comparase una transcripción al azar con alguna monografía del periodo Muromachi cayera en una profunda confusión. Esto no es por descuido o negligencia de los religiosos, sino porque éstos asignaban una nomenclatura europeizada a unos títulos japoneses que no tenían porqué corresponderse con las instituciones de los occidentales.

...En Japón abra de cuatrocientos años, conforme sus escrituras que obedecían todos a un supremo señor, que residía en el Meaco, que es la cabeza de todo Japón, que se llama Cubuçama. ${ }^{15}$ Vinieronse a levantar los señores que le estaban sujetos, de manera que se fueron a dividir en sesenta y seis reinos; y quedó el Cubuçama solamente con el título de su dignidad, más con muy flaco poder, puesto que no dejan los otros reyes de conocer en el alguna superioridad, y estimarlo en mucho... ${ }^{16}$

Froys no andaba desatinado definiendo al Shogun como el líder efectivo del Japón - conceptualmente no es erróneo catalogarlo como un rey de reyes-, pero se debe hacer alguna matización al respecto. Por ejemplo, el título Shogun no implica realeza, ya que literalmente significa generalísimo que somete a los ejércitos. En este sentido un shogunato o Bakufu ${ }^{17}$ cubre los requisitos para que los europeos lo identifiquemos con una dictadura, generalmente fruto de revueltas militares, lucha entre clases, o, simplemente, de una búsqueda desmesurada de poder político protagonizada por algún personaje relevante. Así los shogunes fueron militares preponderantes que sometieron otros territorios y fueron aglutinando poder, por lo que en realidad el término «rey» usado en los escritos

${ }^{14}$ Literalmente, plebeyos.

${ }^{15}$ De esta forma se denominaba a los shogunes al comenzar el periodo Muromachi.

${ }^{16}$ Froys, L. 1575. «De una que el padre Luís Froys escribió de la ciudad del Meaco a los padres hermanos de la Compañía de Jesús de la China y de la India. Febrero 1565», en J. Íñiguez de Laquerica (ed.), Cartas que los padres y hermanos de la Compañía de Jesús escribieron: 4. Alcalá.

${ }^{17}$ Literalmente gobierno detrás de la cortina. La palabra proviene de Ibaku, el telón que usaban los samuráis para urdir sus estrategias en batalla. Como los shogunatos eran dictaduras militares, se usó el término a guisa de metáfora. 
obedece más al concepto europeo «señor de feudo», llamado específicamente daimyo por los japoneses. ${ }^{18}$

En cuanto a los sesenta y seis reinos, era la manera en que los religiosos llamaban a los daimiatos, territorios cuasi-independientes, regidos por samuráis de linaje, pero que debían oficialmente obediencia al shogun de Meaco, la por entonces capital japonesa y actual Kioto.

La degeneración de los diferentes bakufus estuvo directamente relacionada con la pérdida de poder del shogun, tal y como le ocurrió a la dinastía de los Ashikaga, dirigentes débiles, prácticamente nominales, y cuya importancia era más simbólica que real. De ahí el comentario de Froys, que decía «y quedó el Cubuçama solamente con el título de su dignidad». Ante esta manifiesta debilidad del poder central es fácil entender la siguiente anotación del portugués: «...las guerras son muy continuas, fundadas en la codicia que unos señores tienen en señorear a otros, y de tomarles las tierras...».

El Sengoku (1467-1615) fue un periodo muy largo en la historia de Japón que supuso una guerra civil masiva entre los distintos daimiatos. Los distintos señores feudales pretendían alcanzar el poder sobre la mayor parte del territorio, intentando controlar las principales ciudades del centro de las islas, como Edo, $\mathrm{Nara}^{19} \mathrm{o}$ Kioto. Este fue el contexto en el que los religiosos hubieron de expandir la fe de Cristo, una guerra tan cruenta como interminable pero que a su vez elevó a diversos personajes a la categoría de mito. ${ }^{20}$

Así pues nos hallamos ante una red de señores feudales que a su vez disponen de samuráis de diversos rangos, supeditados, al menos sobre el papel, a un Cubusama o generalísimo que trataba de despachar la política desde Meaco. ${ }^{21}$ Pero, ¿sería este título de Cubusama el que distinguiría al jefe de Estado de Japón? O dicho de otra forma, ¿había alguien por encima del Cubusama? Antes de desvelar estas incógnitas veamos cómo continúa el lisboeta:...ay otro señor en el Meaco de dignidad entre las sectas que entre los iapones es como cabeza de Iapon y casi adorado como pagode...22

Del fragmento se podría desprender una referencia hacia alguna personalidad religiosa, una especie de gran sacerdote que haría las veces de patriarca religioso

\footnotetext{
${ }^{18}$ Recordemos que en la historia de Japón se distinguen tres shogunatos. El contexto en el que se desenvolvieron estos religiosos se ubica entre el segundo y el tercero.

${ }^{19}$ Antigua capital de Japón antes del periodo Heian.

${ }^{20}$ Este periodo dejó muchos hechos destacables, aunque tal vez ninguno como la llamativa rivalidad entre Takeda Shingen y Uesugi Kenshin, daimyos de Shinano y Echigo respectivamente. La historia del primero fue adaptada libremente por Akira Kurosawa en Kagemusha, la sombra del guerrero (1980).

${ }^{21}$ Para saber más, Duus, P.1969. Feudalism in Japan. Nueva York. Knoft.

${ }^{22}$ En la documentación consultada significa «símbolo» o «ídolo» religioso. En un principio no guarda relación con la pagoda, el templo budista, salvo porque ésta también es en sí un símbolo religioso.
} 
de Japón. Sin embargo la cuestión es del todo diferente; a pesar de que los misioneros rara vez lo especifiquen el «otro señor de Meaco» es el Emperador de Japón, también llamado Mikado o más específicamente Dairi. El Mikado era el verdadero elemento cohesionador de las islas, un figura que hacía ya mucho tiempo dejó de tener poder político aunque siguiese asumiendo la imagen oficial del país. Luís Froys aportaba esta esclarecedora definición:

...trabajamos mucho el padre y yo para ver si podíamos alcanzar del Dayrim (que es rey absoluto de todo Iapon, más de ninguno obedecido, estante en sus palacios como pagode, de donde nunca sale) una patente para podernos tornar al Meaco, porque sin ella era imposible... ${ }^{23}$

Encerrado en su jaula dorada de Kioto el emperador no gobernaba, mucho más interesado en los tejemanejes de la corte y en la escritura de algún poema licencioso. No obstante, dicha figura siempre ha sido muy respetada en Japón y no fueron pocas las familias advenedizas que, una vez en lo más alto del escalafón social, intentaron emparentarse con los descendientes de Amaterasu. ${ }^{24}$ Incluso en algunos escritos se llegó a comparar la figura del Dairi con la del papa, y es cierto que el emperador era el representante supremo de las religiones japonesas, aunque otorgando preponderancia al shinto, religión nacional. ${ }^{25}$

Asumiendo lo imperfecto de la comparación, sirve para imaginarnos la definitiva estructura política, siempre tortuosa y complicada, del Japón que vieron los misioneros: un poder religioso/representativo que prácticamente no intervenía en nada; un ejecutivo personificado en el Cubusama, tan inestable como el mismo terreno japonés; y finalmente una legión de señores feudales que a su vez disponían por debajo suya de un autentico aparato administrativo y militar. Es fácil de suponer que la debilidad del shogun implicaba la alteración de toda la capa señorial, causa principal para explicar el periodo de estados combatientes o Sengoku Jidai.

Pero, ya lo vimos al inicio del artículo, no sólo el emperador, el shogun, y los señores feudales componían la sociedad japonesa del Quinientos. Así lo demostró el padre Gaspar Vilela, que sintetizó bien en su Relación de las cosas de Japón la hermética jerarquía social del periodo:

${ }^{23}$ Froys, L. 1575. «Carta del padre Luís Froys para los padres y hermanos de la compañía escrita en Japón. Junio 1566» en J. Íñiguez de Laquerica (ed.), Cartas que los padres y hermanos de la Compañía de Jesús escribieron: 6 . Alcalá.

${ }^{24}$ Diosa del disco solar según la mitología shintoista. Según la Casa imperial de Japón, Jinmu (660 a.C.), primero de los Mikados, desciende directamente de la diosa, luego los emperadores del Japón tendrían un origen divino.

${ }^{25}$ Sin embargo, la función religiosa del Mikado siempre fue cultual, en ningún caso adoctrinadora o moralizante, como sí lo es la figura papal en Europa. 
Ay en esta tierra cuatro géneros de gente. La primera son caballeros y gente noble, que no anda ociosa, por causa de las guerras que continuamente tienen. La segunda son sus sacerdotes, que casi son tantos como la gente popular. La tercera son mercaderes, que son muchos. La quarta son labradores: no tienen tierras suyas, sino de los señores, y labrándolas dan de tres dos al señor de la tierra, y ellos llevan uno para sustento suyo... (p. 3).

El confucianismo era una religión que imponía una durísima jerarquización social. Los diversos shogunes Tokugawa estructuraron una división inmutable que bebía de la sociedad de los Cuatro Brazos del confucianismo chino: eruditos - en el caso de Japón la élite samurai - los comerciantes, los artesanos y campesinos. Todos, ya fueran labriegos o daimyos, debían ejercer su función en la vida que les había tocado para complacer el mandato del Cielo, la deidad suprema confucionista. ${ }^{26}$ Sinceramente, no es que la división per se aporte muchas diferencias con respecto a otras sociedades, pero sí que se desprenden muchas conclusiones si se observa desde la óptica religiosa confucionista.

En relación con el fragmento, llama especialmente la atención el comentario «los nobles no están ociosos», el gran número de mercaderes y bonzos, así como la enorme presión agraria que sufría el labrador. Es natural que en un periodo de guerras civiles las familias nobiliarias centrasen sus intereses en los méritos militares y de conquista del territorio. Una vez comenzó el shogunato de Tokugawa dicha tendencia desapareció hasta europeizar los usos y costumbres de las élites exteriores; la cetrería, la caza, el teatro noh, el kabuki, así como las grandes celebraciones, ocuparon el lugar que antaño disfrutó el entrenamiento y la táctica militar. De tal forma la masa guerrera se diluyó hasta convertirse, ya a mediados del Genroku, ${ }^{27}$ en funcionarios, guardaespaldas o literatos, muchos de ellos con un talento estimable.

Por otro lado no debemos suponer que el número de mercaderes fuese tan elevado en la segunda mitad del siglo XVI, ya que después de la interrupción del comercio con China, junto a la caótica situación política, es fácil explicar el descenso de la actividad comercial. De nuevo será al final del siglo XVII cuando el colectivo florecerá, asumiendo el protagonismo de los depauperados samuráis en forma de burguesía emergente. Sobre los bonzos hablaremos más adelante.

La presión sobre el trabajador del campo probablemente fue de las más extremas que se han conocido, máxime entendiendo que no nos hallamos ante esclavos o peones por deuda; tan sólo ante unos campesinos que viven exclusivamente para el trabajo de la tierra. Sería muy complicado explicar la docilidad

${ }^{26}$ Para saber más, Bellah, Robert. 1957. Tokugawa religion, Nueva York: The Free Press.

${ }^{27}$ Periodo de auge cultural que coincidió con el ascenso de la burguesía en el último cuarto del siglo XVII. Fue en esta época cuando se extendió el kabuki, el noh, o el ukiyo-e entre otras artes liberales. 
de estos trabajadores del campo japoneses sin entender la norma confucionista. A medio camino entre la religión y la doctrina filosófica, quizá más lo segundo que lo primero, el confucionismo era, como hemos visto, un sistema de relaciones sociales que en la práctica se reducía a una idea fundamental: obedecer al de arriba. ${ }^{28}$

\section{RELIGIÓN JAPONESA Y PROBLEMAS CON LOS BONZOS}

Si en los ámbitos que se han explicado más atrás los europeos hallaron un mundo con multitud de especificidades, es decisivo describir el paisaje religioso del Japón, finalmente la materia prima a moldear o extinguir según el caso. La tarea no es sencilla, pues bien se pudiera decir que Japón tiene muchas religiones en una sola, o muchas filosofías en una misma religión, o bien que dispone de un sistema socio-adoctrinante como filosofía de nación religiosa.

El padre Balthasar Gago nos describe en 1562 una de las principales realidades religiosas del Japón, su enorme diversidad:...ay dos maneras de ídolos: unos que se llaman camis, que son los reyes de Iapon, otros que se llaman fotoques, que vinieron de la China...29

La premisa desde la que hay que partir para entender la religión japonesa es su complejísimo sincretismo. En la escasa dimensión de las islas convivían muchas religiones, autóctonas y extranjeras, y he aquí que el padre Gago nos distingue dos de las más palpables para los cristianos. El shintoismo - a partir de ahora shinto - y el budismo.

Es muy esclarecedor este otro comentario del padre Pedro de Alcaceva:...en Japón se da la diversidad más que en otras partes, porque hay muchas sectas, y acaece ser el padre de una y la madre de otra y los hijos de otra, y no se les da nada dello... ${ }^{30}$

A pesar de la comentada pluralidad religiosa, no está de más remarcar la relevancia de la religión matriz, la más simple de todas, pero que a su vez sirvió de estructura para soportar las aportaciones de las demás. El padre Gago hablaba

${ }^{28}$ Si bien el Confucianismo se introdujo en Japón durante el periodo Yamato (200 d.C.-500 d.C.) no fue hasta el siglo XVII y XVIII cuando los gobernantes tergiversaron su ideario con motivo de justificar el duro sistema social japonés. No obstante, los padres ya pudieron observar en la segunda mitad del siglo XVI cómo el proceso iba tomando forma.

${ }^{29}$ Gago, B. 1575. «De las sectas de Japón. Diciembre 1562», en J. Íñiguez de Laquerica (ed.), Cartas que los padres y hermanos de la Compañía de Jesús escribieron: 1. Alcalá.

30 Alcaceva, P. 1575. «Carta del hermano Pedro de Alceva para los padres y hermanos de la Compañía de Portugal escrita en Goa. Abril 1553», en J. Íñiguez de Laquerica (ed.), Cartas que los padres y hermanos de la Compañía de Jesús escribieron: 8. Alcalá. 
más arriba de los «camis», - de ahora en adelante kamis - , las deidades menores $^{31}$ de la religión nacional japonesa, el shinto, la única autóctona y la predicada por la Casa Imperial. Estamos ante una religión de tipo primitivo, arcaica si se quiere, cercana al animismo, e impregnada con un aire ingenuo y naturalista, incluso naif se podría decir. Prestemos atención a este comentario de Gaspar Vilela:

....adoran todas las cosas, adoran el Sol, adoran la Luna y las estrellas; adoran palos, piedras, culebras... es por cierto para llorar y haber dolor que gente tan aventajada en sus costumbres y tratamiento sean tan ciegos en el negocio de la salvación, adorando palos y piedras... ${ }^{32}$

Mejor no puede ser ilustrado. Para esta religión cualquier objeto era susceptible a ser adorado, ya que defendía que todas las cosas de la naturaleza podían poseer alma; un sacerdote shintoista rendiría culto a la montaña de su aldea al igual que a un lago o al espíritu de su abuelo, ya que los difuntos pasaban a ser directamente kamis para esta religión. Así pues nos hallamos, de alguna forma, ante una religión de politeísmo radical,$^{33}$ en donde el equilibrio con el medio y la mimetización resultaban esenciales.

Los «otros ídolos» a los que se refería el padre Balthasar son los fotoques - a partir de este momento hotokes - los bodhisattvas, santones y budas de la religión budista. El budismo penetró en Japón alrededor del siglo vi procedente de Corea, pero alcanzó poco calado en sus primeros tiempos. No fue hasta el periodo Heian (794-1185) cuando obtuvo preponderancia, siendo entonces adoptado por las élites de Nara y Kioto. El budismo es una religión no teísta que buscaba la realización espiritual del usuario, el despertar del Buda, lo que asentó en Japón la creencia de que al morir el hombre reencarnaba en otra criatura. Dicha evolución en el ciclo del Samsara podía ser en éste u otro plano de existencia ${ }^{34}$ en función de la moral que el individuo haya mostrado en vida. ${ }^{35}$ El misionero sigue:

\footnotetext{
${ }^{31}$ Para saber más, Holtom, DC. 1940. «The meaning of kami» Monumenta Nipponica Enero: 1.

32 Vilela, G. 1575. «Carta que el padre Gaspar Vilela escribió del Sacay a los padres del convento de Avís de la orden de San Benito de Portugal. Septiembre 1565», en J. Íñiguez de Laquerica (ed.), Cartas que los padres y hermanos de la Compañía de Jesús escribieron: 4. Alcalá.

${ }_{33}^{33}$ J. Falero, A. 2006. Aproximación a la cultura japonesa: 73. Salamanca. Amarú ediciones.

${ }^{34}$ En el memorial que Gaspar Vilela escribió a Sacay en 1565, el portugués afirma que los japoneses tienen treinta y seis cielos o planos de existencia celestiales. El sexto de ellos estaba habitado por demonios.

${ }^{35}$ Los campesinos, casi el 75\% de la población, trabajaban sin rechistar según la doctrina confucionista. Para acabar de cerrar el círculo, el buen comportamiento y la sumisión garantizaban una reencarnación en mejores condiciones. Si no en esta vida será en la otra, pensarían.
} 
...los fotoques tienen dos cabeças, que se dividen en diez sectas, y cada día se levantan cabeças para ser ministros del demonio. Uno de estos fotoques se llama Amida. A quiere decir todos los santos, mi, todas las santas, da toda la librería; de manera que este nombro Amida quiere decir todos los santos y santas de los libros... desta cabeça salieron tres sectas y la maior parte de la gente son dellas... ${ }^{36}$

Nos percatamos de que la mayoría de los japoneses eran budistas y que, más concretamente, en este periodo el budismo era pujante. En efecto, la mayoría de los habitantes de las islas adoraban al hotoke Amida Buda, aunque Gago deja claro que las sectas empezaron a proliferar, a multiplicarse, debido en parte a las múltiples interpretaciones de una religión mística y subjetiva.

...ay otra cabeça fotoque que se llama Xaca, hijo de rey, que nació ocho mil veces en cada especie de cosa, y ansi nace Xaca, que quiere decir principio... Por tal entienden que los hombres muertos vuelven a nacer o en hombres o en bestias... desta cabeça salió otra secta a la que llaman Daynix... ${ }^{37}$

No debemos suponer que estas religiones, así como otras en las que no hemos entrado, convivieron sin mezclarse o influenciarse mutuamente. Pronto los hotokes y los distintos avatares de Buda fueron asimilados por los kamis nacionales y viceversa. El acabado final sería una versión más compleja del shinto conocida como Shintoismo Dual, la efectiva religión de la mayoría de los japoneses.

Hemos visto la manera en que el exceso de sectas originó un altísimo número de sacerdotes. No acaban aquí las complicaciones; antes de comenzar el periodo Edo, más o menos a finales del siglo XvI, tenemos constancia de unas treinta sectas budistas que, no sólo disputaban dialécticamente entre sí, sino que en ciertos casos se exterminaban por medio de sus monjes guerreros o sohei. De esta manera, y aparte del vaivén político en busca del poder, veíamos paralelamente cómo los misioneros tuvieron que lidiar con el fenómeno de los bonzos, tan radicales y hostiles como se pueda imaginar, e interesados también en alcanzar el poder territorial que se disputaba en Japón. ${ }^{38}$ Pero no avancemos acontecimientos:

Levantan nos muchos falsos testimonios los gentiles, y especialmente que comemos hombres, y es esta fama ya tan extendida que en todo Japón se dice, que los inventores de esto son los bonzos, y para que se les de crédito, echan nos paños ensangrentados a la puerta de la Iglesia... ${ }^{39}$

\footnotetext{
36 Vilela G. 1575. «Carta que el padre Gaspar Vilela...»: 3.

${ }^{37}$ Gago, B. 1575. «De las sectas de Japón...»: 2.

${ }^{38}$ En la carta de Frois a Francisco Pérez, jesuita que desempeñaba su labor en China, se decía expresamente que el señor de Osaka era un bonzo, más concretamente de la secta Ikko.

${ }^{39}$ Vilela, G. 1575. «De Japón para los padres...»: 9.
} 
No hay que ser brillante para deducir que las relaciones entre misioneros y bonzos no fueron las idóneas. Al fin y al cabo los intereses de ambos colectivos chocaban frontalmente, y si consideramos que el cristianismo, de gran éxito inicial entre los japoneses, suponía una merma en las donaciones de las pagodes, es fácil entender este tipo de estratagemas tan retorcidas.

Esto lo ilustra el memorial de Pedro de Alcaceva: En este tiempo levantaron los bonzos otra murmuración, diciendo, que los que se hacían cristianos era por no dar limosna a las pagodes... ${ }^{40}$

Así que el pueblo japonés no sólo debía aportar dos terceras partes de su cosecha y humillarse ante los samuráis, sino que también eran explotados por la boncería de una forma atroz: inculcándoles miedo. No era extraña la venta de sellos que garantizasen la protección contra demonios ${ }^{41} \mathrm{o}$ incluso monjes que se lucraban garantizando que eran avatares de Buda.

Luís de Almeyda y Gaspar Vilela relatan estos fenómenos respectivamente: ${ }^{42}$ Es costumbre de estos gentiles en su vida comprar muchas reliquias y perdones para la otra, y ay muchos que por salvarse gastan en esto todo cuanto tienen... ${ }^{43}$

Aprovecharse de la gente humilde es deporte abyecto, ya sean bonzos o cristianos los que perpetraran el engaño, que también los hubo con sotana vendiendo bulas de salvación en Europa. Mucho más amable, por lo simpático del asunto, es el fragmento del Padre Gaspar:

Sepa que hay un bonzo en estos reynos a quien los cristianos por nombre llaman Anticristo del Japón, y los gentiles discretos, engañador de gentes. Es hombre de bajo linaje, pequeño de estatura y muy poco apacible, idiota, sin ningunas letras e inteligencia ... pero tiene impreso el bonzo la malicia del demonio, que le da soltura al hablar: un Demóstenes en la elocuencia de Japón... Vistióse de piel de oveja y andóse de reyno en reyno peregrinando y diciendo que era una revelación altísima del mismo Xaca... ${ }^{44}$

Personajes pintorescos a un lado, no sólo fueron los bonzos los que envenenaron con hechos y verbo la imagen de los occidentales; también éstos se

\footnotetext{
${ }^{40}$ Alcaceva, P.1575. «Carta del hermano Pedro de Alcaceva...»: 8.

${ }^{41}$ Para saber más, Hearn, L. 1904, Kwaidan (Hoichi, el monje sin orejas). Madrid. Alianza.

${ }^{42}$ El mismo Froys relató en ese memorial cómo una anciana de sesenta y cinco años se convirtió al cristianismo y quemó delante de una cruz todos sus sellos protectores: sudarios, kimonos, exvotos e ídolos, todos ellos cubiertos en letras chinas.

${ }^{43}$ Froys, L. 1575. «De una del padre Luís Froys del Sacay para el padre ministro del colegio de Goa. Enero 1566», en J. Íñiguez de Laquerica (ed.), Cartas que los padres y hermanos de la Compañía de Jesús escribieron: 20. Alcalá.

${ }^{44}$ Vilela, G. 1575. «Carta que escribió el padre Gaspar Vilela a un hermano de Portugal en Conchin. Febrero 1561.», en J. Íñiguez de Laquerica (ed.), Cartas que los padres y hermanos de la Compañía de Jesús escribieron: 21 . Alcalá.
}

Hispania Sacra, LXVI

133, enero-junio 2014, 75-107, ISSN: 0018-215X, doi: 10.3989/hs.2013.047 
despachaban a gusto con los bonzos, unas veces con razón, la mayoría de veces sin ella. Obsérvense los dos fragmentos que siguen y apréciense los puntos en común:

Dizen también que somos demonios encerrados en cuerpos de hombres, y que lo que dezimos es por sugestión del demonio... ${ }^{45}$

...ay algunos que adoran al demonio y cuando se quieren dar a este culto vanse a las montañas y alli aguardan varios días al demonio, que se les aparece en forma de venado... ${ }^{46}$

Si no supiéramos la identidad del escritor sería difícil saber quién es el que acusa y quien el acusado, sobre todo cuando desde ambas partes se intentaba dar al traste con la religión ajena mediante argucias y demonios de por medio. Si bien resultaba obvio que los rumores difundidos por los bonzos eran absurdos, también es cierto que el monje no adoraba a un venado maligno, sino probablemente al espíritu de alguna montaña, ${ }^{47}$ generalmente representados como ciervos, jabalíes u algún otro animal de similares características.

Ya ha quedado claro que las relaciones entre los misioneros y la boncería no fueron de lo más cordiales, pero también es cierto que en ocasiones se alcanzó un curioso punto de encuentro, dialéctico, religioso, y filosófico si se quiere, entre miembros de ambas religiones. De estas reflexiones y réplicas los memoriales están llenos, pero hay algunas que destacan al llamar la atención por su inusitada singularidad.

Esto lo plasmó el padre Juan Fernández en los primeros años de estancia en Japón, en 1551:

Preguntaron estos bonzos, que estando el demonio debaxo de la tierra en el infierno, porqué camino venía a este mundo. Respondimos que ansi como las almas de los hombres malos cuando mueren van al infierno, desta manera el demonio va y viene, y que también, que pues el agua al tener cuerpo, tiene por donde vaya, desde un monte alto hasta el profundo, y no le faltan mineros para penetrar en la tierra, no le faltaran tampoco al demonio que no tiene cuerpo... ${ }^{48}$

${ }^{45}$ Vilela, G. 1575. «Carta del padre Gaspar de Japón...»: 8.

${ }^{46}$ Ibídem: 11.

${ }^{47}$ Los hitos naturales de grandes dimensiones como bosques, montañas, ríos, lagos o pantanos, solían poseer un dios titular, un Kami superior que encarnaba el espíritu del territorio. Ejemplo de ello es la ciudad de Nara, cuyo espíritu es un enorme ciervo blanco.

${ }^{48}$ Fernández, J. 1575. "Carta del hermano Juan Fernández para el Padre Maestro Francisco. Octubre 1551», en J. Íñiguez de Laquerica (ed.), Cartas que los padres y hermanos de la Compañía de Jesús escribieron: 2. Alcalá. 
No llama la atención que los japoneses se extrañasen al conocer lo que significaba el averno para los namban. Esto se puede explicar partiendo de las insalvables diferencias que el «infierno» budista guardaba respecto al cristiano. La primera de ellas radica en el número; si bien los cristianos «sólo» padecían un infierno, la cosmología budista creía en varios infiernos distintos según la tipología de transgresión. En este sentido no era lo mismo violar a una mujer que robar comida o matar a un perro.

La segunda de las diferencias es que no se hallaba en este mundo - en el cristianismo está bajo tierra - ya que en la mitología hindú y budista los infiernos son planos paralelos de existencia.

La tercera de ellas, y quizá la que despertaba mayor incredulidad en los gentiles, es la largura del castigo, que duraba solamente siete semanas, las necesarias antes de reencarnar en una criatura más miserable que en la vida anterior - bien es sabido que el hospedaje en el abismo de los cristianos era durante toda la eternidad-.

Finalmente los motivos para ir a tan funesto lugar variaban profundamente entre las mismas sectas; si bien la mayoría de ellas defendía que un alma padecería el castigo por sus hechos en vida, también las había como la secta Shinran que garantizaban la salvación del usuario tan sólo con vocalizar reiteradamente el nombre de Amida Buda. Daba exactamente igual si se habían cometido las mayores aberraciones en vida; la pureza que originaba la creencia en Buda relativizaba todo hecho terreno. Imagínese a un jesuita explicándole a uno de estos bonzos que la promiscuidad implicaba una infernal eternidad sufriendo calvarios de todo tipo. El fragmento sigue de esta forma:

Preguntaron si las almas que van al infierno vienen después aca como demonios. Acerca de lo cual, como sabe vuestra reverencia, tienen muchos errores, diciendo que las almas vienen cada siete días a comer, y les guisan muy bien la comida; y por Agosto quinze días les hacen homenaje sobre las sepulturas, y les encienden lámparas, diciendo que vienen aca... ${ }^{49}$

La mitología asiática está colmada de diversas tipologías de demonios, y en estos seres los japoneses creían mucho. Prácticamente la vida estaba condicionada por este tipo de creencias - más atrás vimos cómo los bonzos llegaban a aprovecharse de esto-; desde los yokais, ogros, narakas o pretas, pasando por una cohorte de duendes, fantasmas y demás seres del otro mundo, la demonología japonesa es un objeto de estudio desde el que se pueden extraer multitud de comportamientos y reflejos socioculturales y de folclore. Quizá debido a ello los japoneses mostraban interés en el retorno de los muertos, tal y como vimos

\section{9 Ídem}

Hispania Sacra, LXVI

133, enero-junio 2014, 75-107, ISSN: 0018-215X, doi: 10.3989/hs.2013.047 
kamis según muchos. Por lo demás la festividad del quince de agosto a la que el padre Juan hace mención, llamada obon, aún hoy se celebra. Muestra de ello dejó el greco-irlandés Lafcadio Hearn,$^{50}$ allá por el siglo XIX, en su excelente literatura de viajes.

El colmo de las antipatías entre religiosos se daba cuando los bonzos iban a reclamar a las autoridades la expulsión de los ibéricos, un fenómeno que se repetía constantemente. Tal fue el caso de Nikiosune, bonzo que demandó a Nobunaga la expulsión definitiva de los jesuitas en medio de una audiencia entre Froys, Toyotomi, el mismo Oda y el Cubusama.

Con un canto en los dientes se hubo de dar el japonés, que recibió la negativa de unas altas esferas que sentían especial predilección por la cultura europea. Llegado el momento, Nobunaga, curioso y dado a probar las habilidades de sus invitados mediante pruebas dialécticas, preguntó a los portugueses la razón de su enemistad con los bonzos, a lo que contestaron que eran ociosos y adoraban a hombres, en clara alusión al origen mortal de los budas. Así se inició un rico y curioso debate:

...ellos - los budas - son hombres como nosotros, los cuales tuvieron mujeres e hijos, y nacieron y murieron, y que a sí mismos no se pudieron salvar ni librar de la muerte, que mucho menos podrían salvar al género humano... ${ }^{51}$

Dando por buena la tesis de que Jesús no era un hombre como nosotros, ni que tuvo mujer o hijos, y que se salvó tanto a él mismo como a la humanidad, la teoría de Froys es irrefutable. Pero claro, ver para creer pensaría Nikiosune, que pidió a Dios nuestro Señor que se manifestase delante suya si era verdad que existía.

...es invisible...

Contestó el padre Lorenzo, acompañante de Froys. El bonzo perseveró en sus cuestiones religiosas preguntando que quién era más antiguo, Dios o Amida:

...Dios nuestro señor antes nunca tuvo, ni principio, ni menos ha de tener fin por ser sustancia infinita y eterna...

Ante esta contestación Nikiosune miró a Nobunaga, instándole nuevamente a echar a los presuntos embusteros, a lo que el militar contestó que siguiese preguntando, ya que así vería sus dudas sofocadas. Se hizo después de esto un silencio que fue roto por Ashikaga Yoshiteru, el shogun, que le preguntó a Froys si el dios cristiano compensaba y castigaba por los actos, a lo que Luis contestó:

\footnotetext{
${ }^{50}$ Para saber más, Hearn, L. 1899. El Japón fantasmal. Barcelona. Satori.

${ }^{51}$ Vilela, G. 1575. «Carta del padre Gaspar Vilela que escribió a un hermano en Portugal...»: 27.
} 
Sí, más esto lo hace en dos maneras distintas; o temporal en esta vida o eterno en la otra.

El bonzo rompió su silencio ante esta aseveración y dijo burlón:

Luego según eso, después del hombre muerto queda dél alguna cosa que reciba premio o castigo... mostrala, pues es la maior gracia del mundo ver esa maravilla...

Tanto Ashikaga como Oda Nobunaga, espectadores de lujo, asistieron al encono del debate, ya que Lorenzo comenzó a alzar la voz:

...el hombre tiene dos formas de ver, una con los ojos corporales, y otra con razón y el entendimiento y como el alma es sustancia pura, y sin ninguna mezcla de los cuatro elementos, no se puede ver con los ojos corporales...

Ante esto el bonzo se levantó y blandió una naginata,${ }^{52}$ dirigiéndose al padre Froys en estos términos:

...pues dezis que queda el alma, teneys me la de mostrar ahora, y para esto tengo de cortar la cabeça a este vuestro discípulo - padre Lorenzo- para que me mostréis la sustancia actual que queda...

Después de esto el padre Gaspar relata una escena que, por fuerza, tuvo que ser antológica, ya que el mismo Ashikaga fue quien redujo al bonzo sujetándolo por la espalda, mientras otros dos daimyos que presenciaban la escena se hicieron con el arma del agresor.

Si el bonzo no acabó alanceado fue porque gestionaba la construcción de varias pagodas y palacios para el Dairi, según Froys, valorados en cuarenta y cinco mil ducados. ${ }^{53}$

He aquí el quid de muchas de las cuestiones.

\section{RAZONES DE LA CONVERSIÓN}

Comete un craso error quien haya interpretado que bajo esta defensa por parte de Nobunaga y el Cubusama existiera alguna simpatía especial hacia la religión de Cristo. Nada más lejos. En el caso que acabamos de ver predomina una curiosidad fuerte, una amistad personal si se quiere, incluso el interés de

${ }^{52}$ Arma de asta con un alfanje en el extremo. Salvando las diferencias recuerda a la alabarda europea.

${ }^{53}$ Froys, L. 1575. «Del padre Luís Froys que escribió desde la ciudad de Meaco en Japón al padre Melchior de Figueredo en Bungo. Julio 1559.» Cartas que los padres y hermanos de la Compañía de Jesús escribieron: 3 . Alcalá. 
un hombre adelantado a su tiempo que comprendió perfectamente el momento histórico al que asistía. Pero repito, casi nunca una afinidad real hacia el cristianismo, al menos en cuanto a las élites se refiere.

Entonces, si salvamos la afinidad que guardaban entre sí Froys y Nobunaga, ¿qué razones hubo para que en Japón encajara de tal forma la norma cristiana? Antes de resolver la cuestión, leamos lo que sigue.

Disponemos de múltiples ejemplos de cómo los daimios sufragaron e incluso promocionaron la empresa jesuita. ${ }^{54}$ Este fue el caso del daimyo de Bungo, que del mismo modo que la mayoría de señores feudales debía dar permiso a los jesuitas para evangelizar sus tierras y convertir a sus súbditos. Un ejemplo de esto lo plasma la carta de Luis de Almeyda en 1564:

...escribió el rey de Bungo al gobernador, que diese casa alos padres donde estar y que los que quisiesen ser cristianos, lo pudiesen ser libremente... ${ }^{55}$

Una vez se aseguraron la simpatía del principal y consiguieron el permiso para impartir la norma entre el pueblo llano, los jesuitas apuntaron más alto. Poco a poco y aprovechando los contactos con los cargos más relevantes del daimiato el mensaje se fue haciendo popular, y muchos chambelanes, administradores, funcionarios, e incluso samuráis de alto rango, decidieron convertirse. Sin temor a equivocarnos podríamos concluir que la religión de los extranjeros se convirtió en una moda estilosa para las élites de Kyushu, una pose diferencial y cohesionadora con respecto al resto de daimyos, y que finalmente acarreaba la relación con miembros de una cultura, en muchos aspectos, superior:

Oyó las cosas de nuestra santa fe Queimindono, que es el señor de aquella tierra, y uno de los mayores que ay en este reyno de Bungo, y gustó tanto dellas, que se estuvo sin comer hasta ahora de vísperas, oyendo y preguntando cosas de nuestra santa fe. De todo lo que se le dijo, mostró quedar muy satisfecho; y puesto que no se baptizó, mostró desearlo mucho y dijo que se hiciera cristiano si supiera la voluntad de su rey... ${ }^{56}$

Así pues los jesuitas practicaban un apostolado vertical preferiblemente de arriba abajo, y eso, lo de llegar hasta abajo, no tenía por qué ser siempre. Sintetizando, el objetivo prioritario serían los grandes señores, para lo cual se dispuso un tipo de política religiosa llamada inculturación; en segundo lugar vendría la élite administrativa, que ya sea por obligación o inercia adoptaba el

\footnotetext{
${ }^{54}$ Para saber más, Braga, JM. 1955. «Jesuitas na Asia». Bolet. Ecles. da diocese de Macau.

55 Almeyda, L. 1575. «Carta del hermano Luis de Almeyda para los hermanos de la compañía de Jesús de la India escrita en Bungo Octubre 1564.», en J. Íñiguez de Laquerica (ed.), Cartas que los padres y hermanos de la Compañía de Jesús escribieron: 3. Alcalá.

56 Ídem.
} 
nuevo credo sin demasiados inconvenientes; y finalmente los campesinos, acaso los más accesibles y predispuestos para ser cristianos de forma real.

De cualquier modo la tipología de adopción religiosa variaba, encontrando en ocasiones a daimyos que abrazaban la norma cristiana individualmente y otros cuya conversión implicaba la de todos sus súbditos: ${ }^{57}$

...escribióme Cosme de Torres, cómo se había bautizado Murandono, que se llamó don Bartholomé, con más de veinte y cuatro o veinte y cinco de los principales señores de los suyos... ${ }^{58}$

La casuística también nos ofrecía líderes que, si bien permitían la doctrina cristiana en su feudo, no la adoptaban por diversos motivos. Hay constancia de que el cuñado de Matsunaga Hisehide, cierto monje shinto, permitía gustoso la adopción del cristianismo a sus fieles, pero él mismo no se convirtió porque perdería una subvención del Dairi rayana los dos mil ducados anuales.$^{59} \mathrm{El} \mathrm{mismo}$ señor de Bungo - Otomo Sorin - no dio el paso en un primer momento ${ }^{60}$, a pesar de la supuesta simpatía que sentía por los europeos:

El rey de Bungo tiene mucha afición a nuestra santa fe, y dize que tiene propósito de hacerse cristiano, pero temiendo de algunas traiciones si él se bautizase antes de algunos de sus principales, aguarda a que ellos lo hagan...

Quizá sea la prontitud de la fecha -1554-, pero La carta del padre Maestro Melchor denota ingenuidad y falta de conocimiento por parte de los jesuitas. Ingenuidad por esperar que un guerrero enfrascado en una cruenta guerra civil, con mil y una prioridades antes que la religión, quisiera verdaderamente bautizarse con tanto entusiasmo. Por otro lado, aceptar la excusa de la no conversión por respeto y prudencia para con sus «superiores» implica un profundo desconocimiento del sistema $h^{6 n^{61}}$ así como de la contextura militar del país.

En efecto, el sistema de daimiatos presentaba dos potenciales superiores para un señor feudal medio: primeramente el Cubusama, generalísimo depauperado,

${ }^{57}$ El cambio de religión de algunos daimios implicaba de facto la conversión de todos sus subordinados y súbditos de señorío. Para saber más, Gil, J. 1990. Hidalgos y samuráis. Madrid. Alianza.

${ }^{58}$ Almeyda, L. 1575. «Carta del hermano Luís de Almeyda para los padres y hermanos de la India, escrita en el puerto de Vocoxiura. Noviembre 1563», en J. Íñiguez de Laquerica (ed.), Cartas que los padres y hermanos de la Compañía de Jesús escribieron: 20. Alcalá.

${ }^{59}$ Froys, L. 1575. «Carta del padre Luís Froys para los padres y hermanos de la Compañía escrita en Japón. Junio 1566», en J. Íñiguez de Laquerica (ed.), Cartas que los padres y hermanos de la Compañía de Jesús escribieron: 9. Alcalá.

${ }^{60}$ Otomo Sorin se terminó bautizando, pero lo haría veinticuatro años después, en 1578.

${ }^{61}$ Han es cada feudo o territorio gestionado por un Daimyo. Cuando nos referimos al sistema Han se alude a la atomización de poder y diversidad de los gobiernos independientes, así como sus relaciones de coexistencia.

Hispania Sacra, LXVI

133, enero-junio 2014, 75-107, ISSN: 0018-215X, doi: 10.3989/hs.2013.047 
sin riendas que controlasen nada y para colmo asistente a los últimos años de su dinastía; y segundo, los señores feudales más poderosos, sobre el papel del todo independientes, pero de hecho peligrosos si se les daba motivos para invadir debido a alguna extravagancia - una religión extranjera podía ser un perfecto motivo - . Se daba la paradoja de que los Otomo de Bungo eran de los clanes más poderosos de Japón, con una renta anual de más de 400.000 kokus, ${ }^{62}$ por lo que a pocos les tendría que rendir cuentas el zalamero daimyo. Dicho de otro modo, este señor feudal mintió descaradamente porque, si bien no deseaba bautizarse, tampoco deseaba perder el contacto con los misioneros.

Pedro de Alcaceva hizo notar que los daimios incluso llegaban a proteger físicamente a los misioneros de los bonzos hostiles:

...quando esta multitud de bonzos ven que no pueden vencer a nuestros padres en las disputas, vénganse en apedrearnos de noche la casa, y algunas veces también nos apedrean en los caminos, más no osaban descubiertamente hacernos mal, por miedo del Rey... que si hallase alguno tirando piedras, cualquiera que fuese, se lo llevasen sus hombres de armas atado de pies y manos, que él le daría el castigo que mereciesen... ${ }^{63}$

La cuestión parece cada vez más enrevesada. Por un lado observamos cómo Otomo Sorin, daimyo de Bungo, negaba mediante infundadas evasivas una hipotética conversión; por el otro, vemos el trato excelente que los señores feudales le procuraban a los padres de la compañía, no sólo en materia de defensa personal, sino también en cuestiones de hospedaje y, esto sí que llama la atención, construcción de Iglesias. ${ }^{64}$ Luego si estos señores no se sentían cristianos, y a fe cierta que no les había dado tiempo a sentirse así, ¿por qué el empeño de mantener contentos a los misioneros extranjeros?

Intentemos explicar las tres principales razones.

\section{Primera, el comercio y la religión entrecruzados}

Los misioneros siempre iban acompañados de comerciantes y esto no pasó desapercibido para los grandes señores feudales, recordemos, en plena guerra civil. Imaginamos que los mercaderes europeos fueron un bálsamo, una salida comercial venida del cielo, en un contexto de guerra que impedía el libre

${ }^{62}$ Unidad para estimar la riqueza en Japón hasta la Restauración Meiji. Los kokus eran medidas de volumen de arroz que oscilaban sobre ciento cincuenta kilos, más o menos lo necesario para mantener a una persona durante un año. Para ser daimyo, la renta anual mínima había de superar los 10.000 kokus, aunque de hecho casi todos los señores feudales rebasaban muy holgadamente esta cifra.

${ }^{63}$ Alcaceva, P. 1575. «Carta del padre Pedro de Alcaceva...»: 5.

${ }^{64}$ Ibídem: 1 
comercio y la obtención de recursos. Pero entonces ¿por qué no sofocar las necesidades comerciales con la todavía pujante China de los Ming? Debido a que las relaciones se cortaron a raíz de los continuos expolios y atentados que los wakus $^{65}$ pertrechaban en tierras de El Celeste Imperio. Este cisma aisló más que nunca a los japoneses, que por nada del mundo quisieron que los jesuitas abandonasen sus tierras, ya que de hacerlo perderían este lucrativo comercio. El lector se preguntará con razón por qué los misioneros y comerciantes debían ir de la mano, es decir, qué impedía a unos y a otros seguir diferentes caminos. Normalmente los comerciantes iban y venían en sus naos cargados de mercancías que vendían para adquirir otros bienes y partir de nuevo. El desconocimiento del idioma y de la cultura japonesa en general hacía perentoria la ayuda como intermediarios que los religiosos prestaban. Otra forma de decirlo: los jesuitas eran potenciales captadores de comerciantes, la verdadera trastienda de los intereses que perseguían los señores de feudo japoneses. ${ }^{66}$

Y que conste que los jesuitas no se iban de vacío. El tópico de misionero acomodado dio para muchos reproches entre órdenes e instituciones, pero aquí, sin rubor alguno, Valignano admite la simbiosis:

...después de Dios, la misión japonesa depende de la Nao do Trato.$^{67}$

Sobran las palabras.

Segunda, las potencias más grandes del mundo

Es de justos reconocer el desconocimiento que los japoneses presentaban en cuestiones geográficas. Japón, archipiélago que ha vivido casi la totalidad de su historia dándole la espalda al mundo, ni conocía ni tendría razón para conocer la inmensidad del globo. De hecho resulta muy esclarecedora en este aspecto la creencia de los nipones que elevaba el número de naciones mundiales a tres: la de ellos mismos, la China, y la India:

\footnotetext{
${ }^{65}$ Piratas japoneses que montaban en una barcaza característica llamada wako. Sus correrías propiciaron la ruptura comercial entre Japón y la China Ming, lo cual incentivó las relaciones entre nipones e ibéricos. Muchísimas crónicas de españoles, ingleses y holandeses recogen encuentros con estos piratas, tildados de salvajes según la documentación.

${ }^{66}$ Para saber más, Bernard, H. 1938. «Les debuts de relations diplomatiques entre le Japon et les spagnols des Iles Philippines (1571-1594)». Monumenta Nipponica 1: 99.

${ }^{67}$ Cabezas, A. 1994: 103.
} 
Los Iapones, por el poco comercio que siempre tuvieron con naciones estrañas, por su cosmographia y mathematica, tienen dividido el globo del mundo tan sólo en tres partes, Iapon, China y Sion, porque hasta ahora parece que no tuvieron noticias de más gente... ${ }^{6}$

De esta forma es fácil imaginarse el impacto que causaron los europeos, tan diferentes y en algunos aspectos superiores a las culturas orientales. La enormidad de sus barcos o el conocimiento sobre armas tan destructivas como el arcabuz elevaron la imagen de los occidentales hasta el punto de generar cierto complejo de inferioridad en los nipones. Esta afirmación, con todo lo arriesgada que pueda llegar a ser, se fundamenta cuando el japonés comprendió el papel que ejercían los portugueses y sobre todo los españoles en el panorama mundial del momento.

Y aquí llegamos a la clave de la cuestión. ¿Qué mal podría conllevar el permitir que unos extranjeros impartan su doctrina si a cambio puedo obtener la amistad de los reyes más poderosos del mundo? A esta reflexión seguramente llegarían multitud de daimyos, vuelvo a repetir, en un contexto de guerra absoluta.

\section{Tercera, los señores de fuera}

No sólo fueron los Otomo de Bungo, sino prácticamente todos los daimiatos del Sureste de Japón, los que abrazaron gustosamente la doctrina católica, ya sea de manera interesada o no. Esto lo deja claro Luis de Almeyda:

...esta provincia de Iapon son dos islas principales, que abra de una a otra no más de media legua, y en esta primera -Kyushu - ay tres reyes... el primero y más poderoso es el rey de Bungo, el cual puede poner en campo a cien mil hombres armados en tres días; los otros dos son los reyes de Arima y Saçuma, a donde estuvo el padre Francisco un año $y$ dejó hondo calado... ${ }^{69}$

De esta forma creemos que las características diferenciales existentes en la zona de Kyushu resultaron decisivas para la rápida expansión del cristianismo en relación a otros territorios. Es hora pues de establecer, aunque sea someramente, las diferencias básicas que podemos hallar en el suelo japonés, bajo nuestro parecer dividido en tres zonas: la ya citada de Kyushu, la isla de Honshu, y la isla de Hokkaido. ${ }^{70}$

\footnotetext{
${ }^{68}$ Froys, L. 1575. «De una que el padre Luís Froys escribió en la ciudad del Meaco...»: 5.

${ }^{69}$ Almeyda, L. 1575. «Carta del hermano Luís de Almeyda...»: 20.

70 Según esta división, la cuarta gran isla de Japón, Shikoku, se insertaría bajo el espectro de Honshu.
} 
Estas diferencias derivan de la geografía del país y sus sistemas de gobierno y administración, incapaces de llegar a unos extremos del archipiélago donde se daban estilos de vida alejados de los postulados que se imponían desde Nara, Kioto, o Edo. En Hokkaido, por ejemplo, la isla más septentrional del Japón, el nivel de civilización y desarrollo se encontraba muy estancado. Aquí florecieron las culturas de los emishi, levantiscos en Heian que mantuvieron usos y costumbres propios del neolítico hasta el siglo XIII.

Por su parte, en Kyushu siempre corría un aire más abierto que en el resto de Japón, quizá por su tradición comercial y sus contactos directos con otras culturas. Este hecho fue generando a lo largo de las generaciones un cierto tono particular y, nos atreveríamos a decir, cierto aire de «independencia» con respecto al resto del país, lo cual degeneró en intereses contrapuestos y disputas entre los daimios del Sureste y el centro de las islas. ${ }^{71}$ A estos señores feudales, junto a otros que podían resultar potencialmente peligrosos, se les impuso un nombre que ilustraba perfectamente el fenómeno: los Tozama o señores de fuera. El cristianismo no vino más que a refrendar estas diferencias; ya no sólo Kyushu era una isla exenta, separada geográficamente del resto de Japón, donde los intereses nacionales importaban poco o nada, sino que además se adoptó una estética religiosa diferente que sirvió como motivo distanciador, otro más, y que terminó de apuntalar el independentismo de Kyushu.

Y sí, el mensaje de la religión era lo de menos.

No obstante a ello siempre hay que huir de los universales, y si hubo moriscos que eran cristianos de corazón, con más razones los habría japoneses. Ahí tenemos el caso de Don Bartholome, daimyo de Omura, a lo que parece cristianísimo, aunque no por ello pacífico o conciliador. Ello se deduce del siguiente fragmento:

Vinieron desde Firando ${ }^{72}$ ciento y cincuenta paraos, formados de a diez hombres de armas y cuatro arcabuceros... más Bartholome les dio guerra y mató más de quatrozientos hombres y otros muchos heridos...Esta batalla fue en el día de San Francisco y dizen que se aparezió una cruz en el cielo. Él entró en batalla con un vestido donde llevaba en el pecho izquierdo una cruz, y en el derecho una corona de espinas con los clavos, y a las espaldas otra cruz, y llevaba por vandera una cruz, que le fue dada por el padre Cosme de Torres... la victoria se la ha dado Dios a Bartholome por ser tan buen cristiano. ${ }^{73}$

${ }^{71}$ Para saber más, Brown, DM. 1955. Nacionalism in Japan. Berkeley. University of California Press CA.

${ }^{72}$ Hirado.

${ }^{73}$ Anónimo. 1564. «Carta que un portugués hombre honrado escribió de Japón al Padre Francisco Pérez, a la China, de las cosas de Japón, y del viaje de los padres que en aquella Nao fueron a Japón. Julio 1564», en J. Íñiguez de Laquerica (ed.), Cartas que los padres y hermanos de la Compañía de Jesús escribieron: 5 . Alcalá.

Hispania Sacra, LXVI

133, enero-junio 2014, 75-107, ISSN: 0018-215X, doi: 10.3989/hs.2013.047 
Costaría creer que tanta producción fuese sólo façade, máxime cuando se sabe merced a otros documentos que este Bartholomé participaba activamente en los ritos de los padres, misas, bautizos, etc.

Mención aparte merecen las clases más bajas, sin duda alguna cristianos de corazón en su mayoría. El lector ya guarda una idea de la difícil situación de estas gentes, y es cierto que los padres se inmiscuyeron mucho en ayudarlas. Por otra parte, y exceptuando la omisión de contribuciones a la boncería local, los labradores y campesinos no debieron hallar ventaja material alguna con su nueva situación religiosa. La espiritual era otra cosa, claro. Además, está demostrado el sustrato cristiano que enraizó en el Sureste, protagonista de numerosísimas revoluciones de tono religioso y agrarista - como las de Shimabara y Amakusa $-{ }^{74}$ y que pervivió incluso después de la expulsión de los europeos y la prohibición del cristianismo a manos de Iemitsu. Yendo más allá, incluso después de la Revolución Meiji se hallaron numerosas comunidades - kakure kirishitan - que habían estado practicando el cristianismo durante generaciones en la clandestinidad.

Si eso no es fe verdadera, que baje Dios y lo vea.

\section{Algunos hechos Políticos}

En las numerosísimas relaciones que los padres escribían también había cabida para los hechos políticos que iban dando forma al Japón moderno. Estas crónicas a veces adolecen de argumentos explicativos, llegando a ser ininteligibles por separado. Sin embargo, cuando los jerarcas de Goa o Macao recibían dichas cartas y las reinterpretaban en conjunto, quizá pudieran ser capaces de atisbar la convulsión general que padecía el país del Sol Naciente.

El valenciano Cosme de Torres se preocupó de hacer notar el peligro que conllevaba la evangelización en un país donde la guerra podría sorprender en cualquier momento, ${ }^{75}$ aunque para peligrosa la aventura que vivieron en 1553 Juan Fernández, Balthasar Gago, Duarte da Silva y el mismo Cosme, que presenciaron la Revuelta de Bungo in situ:

\footnotetext{
${ }^{74}$ Levantamiento que implicó en su mayoría a cristianos japoneses. A pesar de la naturaleza civil de los insurrectos el movimiento puso en jaque la seguridad del shogunato en 1637. Amakusa Shiro, según creían muchos, la nueva reencarnación de Cristo, se convirtió en la cabeza visible de unas gentes que ya no soportaban los impuestos desmedidos y los abusos de las élites. Finalmente fueron arrinconados y reducidos por las tropas shogunales, en colaboración con la flota holandesa.

${ }^{75}$ Torres, C. 1575. «Otra del padre Cosme de Torres de Amaguche para el padre Maestro Francisco en Bungo. Octubre 1555», en J. Íñiguez de Laquerica (ed.), Cartas que los padres y hermanos de la Compañía de Jesús escribieron: 13. Alcalá.
} 
Quando volvimos de Amanguche ${ }^{76}$ a Bungo encontramos la ciudad muy alborotada, por tres grandes señores que querían matar al rey... Llegando el hermano Juan Fernández. al palacio hallólo lleno de caballeros, todos tan apretados y rebueltos, que no se conocían quienes eran los traydores y los amigos... ${ }^{77}$

Los intrépidos jesuitas habían presenciado un fenómeno que hubo de repetirse centenares de veces durante el Sengoku. El Gekokujo, que viene a significar «el pez pequeño se come al pez grande» se daba cuando una coalición de samuráis menores se unía para conquistar un daimiato, que podía ser el propio como es el caso, considerándose entonces un golpe de Estado en toda regla. ${ }^{78}$

Pero recordemos que el agraviado era Otomo Sorin, poderosísimo señor que despachó el asunto con presteza:

Fueron muy rápidamente destruidos dos de aquellos que querían matar al Rey, uno de ellos se llama Fatorindono, otro de ellos Hichimandono, y Eubocatandono: ${ }^{79}$ señores de título, a los quales mandó el rey matar con todos sus hijos y mujeres, parientes, y otra mucha gente... ${ }^{80}$

La aniquilación total de los familiares se trataba de una medida extendidísima en la Historia de Japón. El honor del bushido exigía la venganza y hubo muchos supervivientes de masacres que llegaron a exterminar a clanes enteros. Tal fue el caso de Minamoto no Yoritomo, perdonado durante el exterminio del clan Genji por ser un niño para tiempo después formar un ejército y derrotar a los Taira en Las Guerras Gempei (1180-1185). ${ }^{81}$ Se conocen casos de extrema crueldad en estas prácticas, especialmente las de El sitio de Hoganji ${ }^{82}$ y la Tumba de los traidores ${ }^{83}$ hechos pertrechados por Nobunaga Oda y Toyotomi Hideyoshi

76 Sin castellanizar daimiato de Amaguchi, actual prefectura de Yamaguchi, en la región de Chugoku.

${ }^{77}$ Alcaceva, P. 1575. «Carta del hermano Pedro de Alcaceva para los hermanos...»: 4.

${ }^{78}$ Akira Kurosawa recreó este fenómeno de forma magistral en su inolvidable Ran (1980).

${ }^{79}$ En realidad, Satori, Hashima y Onugata. El dono (tono) final en sus nombres se trataba de una fórmula de sumisión privativa de la nobleza que vendría a significar Señor. Probablemente los misioneros confundieron este tratamiento con la parte final de su onomástica o quizá con algún tipo de filiación.

${ }^{80}$ Alcaceva, P. 1575. «Carta del hermano Pedro de Alcaceva para los hermanos...»: 4.

${ }^{81}$ Conflicto militar a finales del periodo Heian (1180-1185) que enfrentó a los clanes Taira y Minamoto. Esta batalla propició la caída de los Taira y el ascenso de la clase samurai, por lo que es capital en la historia de Japón.

${ }^{82}$ Asedio que Oda Nobunaga impuso en 1570 a la abadía de Ishiyama Hoganji, de la secta ikko, siempre una piedra en la sandalia del general. Cierta noche de tormenta Oda exterminó a los familiares de los monjes cuando éstos aprovechaban para escapar, lo que destruyó la moral de los ikko, que claudicaron.

${ }^{83}$ Hideyoshi siempre estuvo obsesionado con la descendencia debido a su presunta infertilidad. Por ello mismo adoptó a Hidetsugu, miembro de los Oda. Sin embargo, ya en su vejez, en 1593, Toyotomi tuvo por fin su tan ansiado hijo de sangre. Esto ocasionó que Hidetsugu fuese un problema, por lo que lo exilió al Monte Koya dos años hasta que le exigió que se hiciese el harakiri. Los miembros de la

Hispania Sacra, LXVI

133, enero-junio 2014, 75-107, ISSN: 0018-215X, doi: 10.3989/hs.2013.047 
respectivamente. Estas acciones relativizan o desmitifican la figura amable del samurai que la literatura nos ha transmitido.

Dicha crueldad se podría aplicar perfectamente a nuestro «cristiano» señor de Bungo. Ya en 1557 el poderío de los Otomo cada vez se extendía más ${ }^{84}$ colocando a un hermano del daimyo como señor en Yamaguchi, primer daimiato en la isla de Honshu. Para ello no se dudó en exterminar a toda la familia del rival por medio de un subterfugio conocido: provocar una revuelta entre sus propios vasallos.

Para no crear digresión, los Otomo pasaron también a cuchillo a todos los samuráis que se manifestaron en contra del nuevo «rey»:...De manera que veynte días después que llegué a Amanguche mataron al rey y a sus hijos, y alçaron por rey a un hermano del rey de Bungo... ${ }^{85}$

Nótese cómo los religiosos hacen mutis por el foro no mencionando a Otomo ni extrayendo conclusiones de un hecho tan evidente. Después de todo el implicado es un amigo de la religión cristiana que sufraga gastos, protege misioneros y construye iglesias. Mejor era mirar hacia otro lado.

$\mathrm{Al}$ año siguiente el clan Otomo recibiría un duro golpe en forma de sendos incendios que destruyeron prácticamente sus ciudades. Bungo y Yamaguchi eran las puertas a la isla de Kuyshu y actuaban de marcas fronterizas protegiendo a los otros dos daimiatos restantes, más débiles en aquel momento. Por ello no es difícil pensar que muchos señores rivales intentasen destruir estas ciudades desde dentro, ya fuere comprando a algún subordinado de confianza, adquiriendo los servicios de asesinos ninja, envenenando los pozos, cortando los abastos, e incluso quemando la ciudades, como fue el caso. La medida que tomó el señor de Bungo fue tan expeditiva o más si cabe que las anteriores. Según las pesquisas, trece familias eran sospechosas en mayor o menor grado de haber intervenido en los atentados. Pues bien, Otomo acabó absolutamente con todos sus integrantes, desde los samuráis, pasando por las mujeres, niños e incluso el servicio. Ni las casas de los sospechosos se salvaron de la quema, nunca mejor usada la expresión, siendo reducidas a cenizas ${ }^{86}$ Como el lector puede observar, en el Japón de la época no existía la presunción de inocencia.

familia de Hidetsugu fueron asesinados en Meaco, entre ellos treinta y un mujeres y varios niños. Se arguyó que conspiraban contra el Taico, erigiéndoseles un mausoleo que pasó a ser llamado «La tumba de los traidores».

${ }^{84}$ En ese mismo año Gaspar Vilela nos narra en primera persona cómo Otomo destrozó en batalla tanto al rey de Firando como a su cuñado.

${ }^{85}$ Torres, C. 1575. «Carta del padre de Cosme de Torres de Japón para los padres y hermanos de la Compañía de Jesús en Portugal. Noviembre 1557», en J. Íñiguez de Laquerica (ed.), Cartas que los padres y hermanos de la Compañía de Jesús escribieron: 2. Alcalá.

${ }^{86}$ Melchor, P. 1575. «Carta del Padre Maestro Melchor, provincial. Enero 1558», en J. Íñiguez de Laquerica (ed.), Cartas que los padres y hermanos de la Compañía de Jesús escribieron: 3 . Alcalá. 
La quema de ciudades fue muy recurrente en la historia militar de las islas. Después de todo era una acción que se podía llevar a cabo con pocas personas, tres o cuatro, y que resultaba muy destructiva. Tenemos un extracto de la quema de Yamaguchi, acaecida en este mismo año de 1558:

... pero como el oficio del demonio sea sembrar zizaña en el campo del Señor, con que ahogue el trigo, sembró tan grande discordia entre dos señores que tenían el gobierno de Amanguche, que peleando entre sí, como el pelear de los iapones sea con fuego, y las casas todas de madera y papel, sin ningún género de pared, estendiose de tal manera el fuego que en muy breve tiempo se quemó toda la ciudad, que según dizen era como Lisboa... ${ }^{87}$

Faltaría espacio para enumerar las quemas de ciudades que se sucedían continuamente. Pero sirva como ejemplo uno de los más ilustres y modernos, la quema de Kioto durante las Guerras Boshin ${ }^{88}$ en el contexto del asunto de ikedaya, sucedida en 1864, y que nos muestra que este método no se perdió con la «paz» de doscientos cincuenta años que propició el shogunato de Tokugawa. Estos contratiempos supusieron para los religiosos trabas continuas, y en el caso más específico de Amaguchi se perdieron ocho años de evangelización en apenas un día. Resulta al menos curiosa la manera en que el cristianismo demostró haber calado en este lugar, ya que en los sótanos de las casas calcinadas se hallaron muchos templetes donde se adoraban cruces y otros ídolos que el mismo Cosme de Torres trató de rescatar y conservarlos a guisa de reliquias. ${ }^{89}$

Podemos imaginarnos a ciencia cierta la comprometida e incómoda situación de los jesuitas, por lo que era natural la marcha de muchos ante el aluvión de dificultades que se debían superar a diario en una isla tan tumultuosa. El padre Maestro Melchor no aguantó más esta guerra interminable:

...cay enfermo con los mantenimientos de esta tierra de Iapon, que es arroz, sin otra cosa que le de sabor alguno, y la cama es una estera con un madero en la cabeçera. Fue tan grande mi enfermedad que fue mucho poder venir como una bestia hasta Bungo, donde estuve tres meses con calenturas y fríos, que me pusieron al cabo. No dándome el Señor salud, y viendo que por entonces se podría hacer poco fruto en Iapón por estar la tierra alborotada con guerras, me fui forzado a embarcarme, ansi enfermo como estaba, en una Nao que venía para la India...90

Tanto el padre Melchor como el señor de Bungo parecieron «presagiar» la comprometida situación de Amaguchi. Una vez la ciudad fue reconstruida, el hermano de Otomo avisó a los misioneros para que reemprendieran su labor

${ }^{87}$ Ídem.

${ }^{88}$ Enfrentamiento armado entre los partidarios de la familia Tokugawa y los monárquicos durante el fin del shogunato, más específicamente durante los años 1868 y 1869. Esta etapa se llamó bakumatsu.

${ }^{89}$ Melchor, P. 1575. «Carta del padre maestro Melchor...»: 2.

${ }^{90}$ Ibídem: 6. 
evangelizadora en la ciudad y así proseguir su camino hacia el centro del país. Sin embargo, Sorin instó a los jesuitas que esperasen al deshielo:

...De Amanguche nos escrivio el Rey y los señores de la tierra, en el mes de Deziembre, pidiéndonos que nos tornásemos allá. Y yendo a pedir licencia al Señor de Bungo, su hermano, sin cuyo parecer no osamos hacer nada... me respondió que aun no era tiempo, que cuando fuese él me avisaría, que ahora estarían los caminos llenos de nieve, que mejor era guardar al verano...91

Si Otomo Sorin sabía lo que iba a ocurrir después o no nunca lo sabremos, pero desde luego se pueden ir extrayendo teorías:

...sospechamos tenerle los suyos algunas trayciones encubiertas, que él sabía, y así fue que un gran señor fue hacía la ciudad de Amaguchi, la cual ya estaba reedificada de la quema, y la destruyó y la derribó, robando y captivando mucha gente y matando al rey, que era el hermano del Rey de Bungo, con todos los de su vando... El rey de Bungo viendo esto embió un grande ejercito, para sujetar aquella tierra...92

Ya sabemos el interés de los daimios por administrar seguridad a los padres, pero si verdaderamente Otomo sabía que un ejército iba a tomar Amaguchi ¿por qué razón su hermano seguía en la ciudad? O hilando más fino ¿por qué no mandó a sus tropas para fortalecer la defensa? Es más, la petición de vuelta a los jesuitas ¿era verdaderamente un deseo religioso del señor de Amaguchi o más bien una desesperada tentativa de procurarse una barrera de seguridad? Conociendo el valor que su hermano les concedía a los religiosos quizá pensase que no se atrevería a atacar Amaguchi con ellos dentro. No obstante, y aunque todo lo anterior son simples teorías, por la mente del lector empezara a cobrar más fuerza la idea de una conspiración cainita, pero los motivos de ésta, de ser real, no están en mi mano desentrañarlos. Tan sólo hay que achacar este comportamiento a una estrategia de vida extrema, donde vives o mueres, condicionada por la aglutinación de poder y títulos, y en el que cualquier día de la vida puede ser el último.

Después de estos hechos los padres tomaron un barco desde Bungo hasta Sacay, donde según dice Luis de Almeyda hubo una contienda y se quemaron setecientas casas. No se acabaron los sustos para los misioneros en su peregrinaje hasta Kioto, ya que en su paso por Osaka presenciaron otro nuevo incendio provocado por la guerra. A cada paso que se daba hacia la capital, zona neurálgica y objetivo de diversos daimyos, las desgracias parecían aumentar:

${ }_{91}$ Torres, C. 1575. «Carta del padre Cosme de Torres...»: 4.

${ }^{92}$ En otro memorial de ese mismo año Luis de Almeyda confirmó la pacificación de la zona y el ulterior asentamiento de Otomo. 
novecientas casas fueron pasto de las llamas ${ }^{93}$ Por si todo esto no fuera poco los padres se iban granjeando una fama de gafes que les hizo ser objeto de agresiones, tanto por parte de vecinos como, sobre todo, bonzos.

De una forma u otra los jesuitas terminaron llegando a la capital del Imperio, donde ya vimos que fueron bien tratados por las autoridades. A lo largo de los años en que los europeos predicaron en Kioto hubo tiempo para construir iglesias, convertir a gentiles y forjar relaciones que trascienden la mera cordialidad. Sobre éstas destacan sobremanera las que se mantuvieron con unos personajes preeminentes en el concierto político del periodo: Ashikaga Yoshiteru, el por entonces shogun, y Nobunaga Oda, el hombre que hubo de poner la primera piedra para la unificación política de Japón y el fin del periodo Muromachi.

El lector ya habrá comprobado de sobras que nadie estaba exento de peligro en el Japón de esta época, ni tan siquiera el Cubusama. Residente en la capital junto al emperador, el shogun era todavía un signo de unidad que muchos perseguían destruir o suplantar. Es cierto que también conservaba adeptos, entre ellos Nobunaga, pero cualquier descuido podría significar la muerte de cualquiera. Otro de estos señores afines a la familia Ashikaga fue Miyoshi - Mioxindono en la documentación castellana-, poseedor de una fortaleza inmensa a once leguas de la capital. El poder que aglutinó este señor de la guerra durante los estertores del Sengoku no hubo de ser poco, ya que mantenía relaciones con varios señores. Uno de sus subalternos más allegados era Dajondono - en realidad Matsunaga Hisahide - en palabras de Froys: el más cruel tirano que nunca uvo en Iapon.

Este Miyoshi visitaba periódicamente al shogun, pero en 1565 lo hizo acompañado de unos doce mil ashigaru ${ }^{94}$ que quedaron apostados a las afueras de la capital. Este hecho descentró a las élites de Meaco, que especularon con un golpe de Estado. Sin embargo, dichas intenciones no respondían a un atentado sobre la ciudad, sino que tan solamente buscaban «rendir homenaje» al Cubuçama instándole a él y su familia a cenar en un monasterio de Bonzos fuera de la misma. Esto, que fue un rapto en toda regla, acabó con la muerte del generalísimo de Japón, el último miembro de Ashikaga que aún conservaba un vestigio de poder político. Así relataba Froys un suceso que vivió en primera persona:

Creciendo cada vez más la maldad destos tyranos, y no pudiendo dilatárseles por más tiempo su perversísimo deseo, prendieron fuego al palacio de Bonzos. Queriendo salirse dél el Cubuçama, abraçose con él su madre, y constreñido del fuego y de la necesidad

93 Almeyda, L. 1575. «Carta del hermano Luís de Almeyda para los padres y hermanos de la Compañía del camino que se hizo con el padre Luís Froys al Meaco. Octubre 1565», en J. Íñiguez de Laquerica (ed.), Cartas que los padres y hermanos de la Compañía de Jesús escribieron: 12. Alcalá.

${ }_{94}$ Hombre de armas de los ejércitos japoneses hasta la Revolución Meiji. Eran soldados con paga propia, muchos de ellos mercenarios, pero no hay que confundirlos con los samuráis, de extracción noble. Solían blandir lanza, wakizashi o espada corta, y a partir de la llegada de los europeos, arcabuz.

Hispania Sacra, LXVI

133, enero-junio 2014, 75-107, ISSN: 0018-215X, doi: 10.3989/hs.2013.047 
salió con los suyos, y començando a pelear diéronle una lançada en el pecho y un flechazo en la cabeça y dos cuchilladas en el rostro, y allí cayó muerto... ${ }^{95}$

Ni que decir tiene, el resto de familiares fue pasado a cuchillo, sin excepción de niños o mujeres, que además fueron ultrajadas por los soldados de Miaxindono. Por lo demás, a los jesuitas se les perdonó la vida por considerárseles extranjeros que nada tenían que ver con Japón.

Según Froys, un caballero cristiano que allí se hallaba le desveló que el verdadero culpable del regicidio fue Hisahide:

...En esto que nos envió recaudo un cavallero cristiano de los principales de Dajondono, diziendo que hombre que contra su Rey y Señor de todo Iapon, había cometido tal traycion, de creer era, que haría fasylisimamente los otros males... por lo qual conbenia que Dajondono ordenó todo esto... ${ }^{96}$

De ser verdad la existencia de tal caballero y su mensaje, Dajondono tendría ascendencia sobre Miaxindono. Esto, que a priori no era así, tampoco es descartable, sobre todo por lo intrincadas y relativas que eran las relaciones diplomáticas en este periodo tan caótico. Después de esto el mensaje histórico de Froys se desacredita, al defender que la muerte de Yoshiteru se debió a una conspiración nacional que iba en contra del cristianismo. ${ }^{97}$

La muerte de Ashikaga Yoshiteru originó una aceleración en los acontecimientos. Oda se erigió en la figura central del Japón de mediados del siglo XvI, y como dije anteriormente, sin su actuación las islas hubieran desembocado en otros derroteros históricos. Es cierto que Nobunaga murió de forma prematura, también mediante una traición urdida en su círculo de hierro, por lo que el orden establecido cambió radicalmente para los religiosos portugueses y españoles. La ascensión del sustituto de Oda, Hideyoshi Toyotomi, el Taicosama de la documentación española, significó el declive de las relaciones entre los misioneros y las élites japonesas. A su muerte en 1598, el espectro del Japón recae por fin en Ieyasu Tokugawa, el Daifusama. Si bien los primeros años fueron de concordia y respeto, la pujanza que alcanzaron los cristianos y sus conversos resultaba incómoda para un hombre que tanto se estaba dejando en controlar Japón. Fue precisamente el nieto de Ieyasu, Iemitsu Tokugawa, tercer shogun, el que impuso la definitiva persecución a los extranjeros y el cierre de Japón en 1641.

${ }^{95}$ Froys, L. 1575. «De otra del padre Luís Froys que escribió del Meaco a los padres y hermanos de Bungo. Junio 1565», en J. Íñiguez de Laquerica (ed.), Cartas que los padres y hermanos de la Compañía de Jeús escribieron: 7. Alcalá.

${ }_{96}$ Ídem.

${ }^{97}$ Froys, L. 1575. «De otra del padre Luís Froys...»: 8. 


\section{Conclusión}

A lo largo de las páginas anteriores el lector habrá podido escudriñar el contexto histórico de los treinta primeros años de estancia ibérica en Japón. Es cierto que muchos de los asertos de estos hombres eran desatinados o subjetivos; también lo es que probablemente los padres no tuvieran como fin preservar este tipo de conocimiento más allá del ámbito privado. Se puede decir de otra forma: los jesuitas no fueron historiadores, al menos conscientemente, ya que la inmensa mayoría de la información estaba destinada a allanar el camino de la evangelización asiática. No obstante, esto no repercute en lo más mínimo a la hora de reivindicar este tipo de documentación, poco utilizada por los estudiosos no dependientes de alguna institución religiosa.

Detalles aparentemente secundarios, como las características climáticas o la feracidad del territorio, son capitales para entender óptimamente el éxito inicial de la norma cristiana, al menos en los estratos más bajos. Tampoco las extravagancias sociales de Japón consiguieron obnubilar la agudeza crítica de estos aventureros, sobre todo, atendiendo al panorama belicista que enmarcaba la estancia jesuita en la isla del Sol naciente. Paradójicamente, tan sólo las referencias religiosas, que son muchísimas, se antojan negligentes, no ya por cerrazón mental o incapacidad intelectual, sino por la parcialidad obvia de quien hipoteca toda una vida a favor de una causa en concreto. Aún así, y casi sin quererlo, los religiosos dejaron apuntes valiosísimos sobre esta fusión religiosa que se dio en Oriente, cuando no protagonizó interesantísimos coloquios junto a sus refractarios japoneses. En este mismo artículo se encuentra una de esas pequeñas joyas que Clío nos regala de vez en cuando: documentos que, sin perder la pátina histórica, se hallan imbuidos por cierta oralidad rayana con la literatura.

\section{BIBLIOGRAFÍA}

Bayle, Constantino. Un siglo de Cristiandad en el Japón. Barcelona - Madrid, 1935.

Bellah, Robert. Tokugawa religion, The Free Press, Nueva York, 1957.

Bernard H. Les debuts des relations diplomatiques entre le Japon et les spagnols des Iles Philippines (1571-1594), «Monumenta Nipponica», nº 1 1938, p. 99-137.

Boxer, Charles R. The Christian Century in Japan, 1549-1650. University of California Press, Berkeley, CA, 1951.

Braga, J. M. Jesuitas na Asia. Bolet. Ecles. Da diocese de Macau. 1955.

Cabezas, Antonio. El siglo ibérico de Japón. Universidad de Valladolid. Valladolid. 1994.

Chanu, Pierre. Les Philippines et le Pacifique des Iberiques. XVIe, XVIIe et XVIIIe siécles, 1960. 
Elison, George. Deus destroyed: The image of Christianity in Early Modern Japan. Harvard University, Harvard, 1988.

Falero, A. Aproximación a la cultura japonesa. Amarú ediciones. Salamanca. 2006.

Gil, Juan, Hidalgos y Samuráis, Alianza Editorial, Madrid, 1990.

Gonsalves, Sebastian. Primera parte da Historia dos religiosos da Companhia de Jesu. (vol. 2, Edición de J. Wicki), 1957-60.

Gutiérrez, Fernando. Japón y Occidente: Influencias recíprocas en el Arte. Sevilla. Guadalquivir Ediciones. 1991.

Holtom, DC. 1940. «The meaning of kami» Monumenta Nipponica. 1: 1-27.

Íñiguez de Laquerica, Juan (ed.), Cartas que los padres y hermanos de la Compañía de Jesús escribieron, Alcalá, 1575.

Jackrtinton, C. The Ophirian conjecture: Hispano-Lusitanian Optimism in SouthEast Asia and Pacific in the XVI Century. Philippine Historical Rewiew. 1965.

Knauth, Lothar. Confrontación transpacífica. El Japón y El Nuevo Mundo hispánico. 1542-1639, México, 1972.

López Garay, J. 1962. «La preevangelización de los primeros años de la evangelización». Missionalia Hispanica. 19: 289-329.

Reyes Manzano, A. 2005. «Mitos y leyendas sobre las relaciones hispano-japonesas durante los siglos XVI-XVII» Brocar. 29: 53-75. 